\title{
Trends, Spatial Pattern and Determinants of Skilled Birth Attendant Utilization in Ethiopia: Data from Ethiopian Demographic and Health Surveys (2005, 2011 and 2016).
}

\section{Lemma Demissie Regassa ( $\nabla$ esraeldemiss@gmail.com )}

Haramaya University Department of Public Health https://orcid.org/0000-0002-5461-5348

\section{Assefa Tola}

Haramaya University College of Health and Medical Sciences

\section{Biruk Shalmeno Tusa}

Haramaya University College of Health and Medical Sciences

Adisu Birhanu Weldesenbet

Haramaya University College of Health and Medical Sciences

\section{Research}

Keywords: Skill of birth Attendant, Spatial Pattern, Ethiopia

Posted Date: September 16th, 2020

DOl: https://doi.org/10.21203/rs.3.rs-73547/v1

License: (c) (i) This work is licensed under a Creative Commons Attribution 4.0 International License.

Read Full License 
1 Trends, Spatial Pattern and determinants of Skilled Birth Attendant Utilization in

2 Ethiopia: Data from Ethiopian Demographic and Health Surveys (2005, 2011 and 3 2016).

4 Lemma Demissie Regassa ${ }^{1 *}$, Assefa Tola ${ }^{1}$, Biruk Shalmeno Tusa ${ }^{1}$, Adisu Birhanu

5 Weldesenbet ${ }^{1}$

$6 \quad{ }^{1}$ Haramaya University, College of Health and Medical Science, Department of Epidemiology

7 and Biostatistics

$8 *$ Corresponding author

9 Lemma Demissie Regassa

10 Contact address: esraeldemiss@gmail.com / lemma.demissie@ haramaya.edu.et

11 Authors address

12 LDR: $\underline{\text { esraeldemiss@gmail.com / lemma.demissie@gmail.com }}$

13 AT: asseharar@yahoo.com / asseharar91@gmail.com

14 BST: birukshalmeno27@gmail.com

15 ABW: adisuebi2009@gmail.com

16

17 


\section{Plain English summary}

20 Skilled birth attendant is defined as a delivery assisted by qualified Medical Doctors (general 21 practitioners, gynecologist or related specialists), Public Health officers, Nurses,

22 Midwiferies, or health extension workers. This study aimed to assess the trends over the

23 time, spatial distribution and determinants of skilled birth utilization in Ethiopia.

24 Data from the three consecutive national health and demographic survey $(2005,2011$, and 25 2016). A total of 32157 pregnant mothers employed for analysis. The trend of skilled birth 26 attendant utilization has been increased from five percent in 2005 to $10 \%$ in 2011 and $27.5 \%$

27 in 2016. Skilled birth was clustered with spatial variation across the country. The primary 28 and secondary significant clusters of skilled birth attendants were located in Addis Ababa 29 and Dire Dawa.

30 Skilled birth attendant's utilization was determined by residence, women's educational level,

31 partner's educational level, age at first birth, maternal age at interview, and antenatal care

32 were significantly associated with SBA utilization.

33 In Conclusion; the Skilled birth assistance utilization has shown a substantial increased and

34 showed spatial variation in Ethiopia. We recommend strengthening maternal health programs

35 with special emphasis for uneducated and women from rural parts of a country. 


\section{Abstract}

38 Introduction: Since 2000, Ethiopia has achieved considerable success in reduction of

39 maternal and child mortality, but progress and distribution across the country in SBA remains

40 unclear. This study aimed to assess the trend, spatial distribution, and determinants of skilled

41 birth attendant utilization in Ethiopia.

42 Methods: Data from time series community-based cross-sectional study design of Ethiopian

43 Demography and Health Surveys (2005-2016 EDHS) were employed. Data was downloaded

44 and extracted from DHS website (www.dhsprogram.com). Stata version 16.0 for statistical

45 and Arc-GIS version 10.1 and Sat-Scan software's were used for spatial analysis. Multilevel

46 generalized linear model with binomial distribution was fitted to identify community and

47 individual level factors associated with skilled birth attendant utilization. Adjusted odds ratio

48 with $95 \%$ confidence interval used to report the association.

49 Result: The trend of skilled birth attendant utilization has been increased from 5\% in 2005 to

$5027 \%$ in 2016. Skilled birth was clustered with spatial variation across the country. The

51 primary and secondary significant clusters of skilled birth attendants were located in Addis

52 Ababa and Dire Dawa. Skilled birth attendant's utilization was determined by residence,

53 women's educational level, partner's educational level, age at first birth, maternal age at

54 interview, and antenatal care were significantly associated with SBA utilization.

55 Conclusion: The SBA utilization has shown a substantial increased and showed spatial

56 variation in Ethiopia. We recommend strengthening maternal health programs with special

57 emphasis for uneducated and women from rural parts of a country.

58 Key words: Skill of birth Attendant, Spatial Pattern, Ethiopia 
61 The world pledged to improve maternal health within Sustainable Development Goal (SDG)

62 to reduce the maternal mortality ratio (MMR) by $75 \%$ and ensure universal access to

63 reproductive health by 2030. Although the global MMR is falling, up to 358, 000 women

64 lose their lives during pregnancy and childbirth each year [1, 2]. Maternal mortality remains

65 a public health priority, with MMRs high (above 300) in 45 countries [2] .

66 According to a joint statement by World Health Organization (WHO), the International

67 Confederation of Midwives (ICM), and the International Federation of Obstetricians and

68 Gynecologists (FIGO), a 'Skilled Birth Attendant' [3] is defined as 'an accredited health

69 professional such as a midwife, doctor or nurse who has been educated and trained to

70 proficiency in the skills needed to manage normal (uncomplicated) pregnancies, childbirth

71 and the immediate postnatal period, and in identification, management and referral of

72 complications in women and newborns [4]. The "percentage of births attended by

73 a skilled birth attendant" is an indicator that has been adopted by several global monitoring

74 frameworks, including the SDG agenda for regular monitoring as part of target 3.1 for

75 reducing maternal mortality by $2030[\underline{5}, \underline{6}]$.

76 Most obstetric complications could be prevented or managed if women had access to a

77 skilled birth attendant during childbirth. Globally, almost 80 per cent of live births occurred

78 with the assistance of skilled health personnel in the latest period 2012-2017 - up from 62

79 per cent in the 2000-2005 period, with largest progress occurring in the last 10 years [ㄱ, $\underline{8}$.

80 However, the estimated coverage of births attended by skilled health personnel between 
81 2012-2017 shows inequality between WHO regions as only 59 per cent of the births in the

82 sub-Saharan Africa Region were attended by skilled health personnel whereas more than

$8368 \%$ to $99 \%$ of all births are attended by skilled health personnel in non-Sub Saharan

84 Regions [9-11]. The utilization of skilled birth attendant (SBA) in Ethiopia is very across the

85 administrative region [12-15]. Among the nine regions and two administrative cities, the Afar

86 region had the lowest utilization (10\%) and Addis Ababa had the highest utilization (86.5\%).

87 Majority of the mothers (84\%) gave birth to their child at home, mainly assisted by relatives

88 and traditional birth attendants (TBA) [16].

89 Factors such as wealth quintile, media exposure, and rural/urban residence were commonly

90 adjudged as significant education of the adolescent mother and her partner were the

91 commonest significant factors that influenced maternal health service utilization. Use of

92 antenatal care also predicted use of skilled birth attendance and use of both predicted use of

93 postnatal care. However, there may be some context-specific factors that need to be

94 considered [17, 18]. This study aimed to assess the trends, spatial distribution, and

95 associated factors of SBA in Ethiopia.

96

97

98

99

100 


\section{Study Design, Setting \& period}

103 A time series community based cross-sectional study design was employed using the

104 Ethiopian Demography and Health Surveys (2005-2016 EDHS) to assess the trends, spatial

105 patterns, and associated factors of SBA care service utilization in Ethiopia. The projections

106 of the 2007 population and housing census showed that the estimated total population of

107 Ethiopia was more than 99 million with a total fertility rate of 4.59 by 2015 . More than $80 \%$

108 of the Ethiopian population are rural habitants. The mean individual per a household was 4.6.

109 There has been a marked decline in the total fertility rate from 1990 to 2015 (from 6.4 births

110 to 4.59 births per woman) in Ethiopia [19].

111 The EDHS is considered as the main data source in the country as it was designed to provide

112 population and health indicators at the national and regional levels. The data collection

113 period was from Nov. 2004 to Jan. 2005 for 2005 EDHS, Sept. 2010 through Jan. 2011 for

1142011 EDHS, and Jan. to June, 2016 for 2016 EDHS. This data analysis was conducted from

115 May 1 to Aug. 10, 2020.

\section{Data Sources}

117 The EDHS was first piloted in Ethiopia in 2000 and a total of four full-scale national surveys 118 (2000, 2005, 2011, and 2016) have been conducted to date. The data were collected by the

119 Central Statistical Agency (CSA) under the supervision of the Ministry of Health (MOH) and 120 technical support provided by the Inner-City Fund (ICF). These surveys deliver pertinent 
121 health and social information (including maternal and child health, trends in key health

122 indicators in population) to monitor policy decisions. This study utilized data from the EDHS

123 of 2005, 2011, and 2016 years. Data also comprised the location data (latitude and longitude

124 coordinates). The data was extracted from Measure Demography and Health Surveys (DHS)

125 website (www.dhsprogram.com) after permission from the host is granted by letter no. 126144625.

\section{Sampling design and sampling process}

128 The 1994 and 2007 Population and Housing Census, conducted by the Central Statistical 129 Agency (CSA) provided the sampling frame (1994 for 2005 and 2007 for 2011 and 2016 130 EDHS) from which samples were drawn. The census contained a complete list of 84,915

131 enumeration areas (EAs). An EA is a geographical area covering on average 181 households

$132[\underline{19}, \underline{20}]$. An EA is a geographic area consisting of a convenient number of dwelling units

133 which served as counting unit for the census. The frame file contains information about the

134 location, the type of residence, and the number of residential households for each of the

135 81,654 EAs. The cluster and household allocation by region and residence are a function of

136 the average number of women 15-49 per household and of the household and individual

137 response rates (obtained from the previous EDHS). A stratified two-stage cluster sampling

138 procedure was used to select the nationally representative sample in all four surveys, with a 139 high overall response rate that ranged from $95 \%$ to $99 \%$. Additional information about data

140 collection, sampling, and questionnaires used in the surveys are described in detail in the 141 respective EDHS reports [21-24]. Because the sample is not self-weighting at the national 
142 level, all data in this report are weighted (using sampling weight for women) unless 143 otherwise specified.

144 In 2005 EDHS, a representative sample of approximately 14,500 households from 540 (145

145 urban and 395 rural) clusters was selected. A total of 14,645 households were selected, of

146 which 13,721 (98.5\% response rate) interviewed. A total of 14,070 (95.5\% RR) eligible

147 women (15-49yrs.) were interviewed, of which 11,163 were giving birth with the preceding

148 five years of the survey period.

149 For the 2011 EDHS, the sample included 624 EAs, 187 in urban areas and 437 in rural areas.

150 In the second stage, a fixed number of 30 households were selected for each EA. A

151 representative sample of 17,817 households was selected, of which $16,702(98 \%)$ households

152 and 16,515 (95\%) women interviewed. The data of $53(8.5 \%)$ clusters were excluded from

153 the spatial analysis as the geographical coordination data was missed.

154 In EDHS 2016, a total of 15,683 (95\%) women in reproductive age were interviewed, but

155 this study used 11,023 women who gave birth in the 5 years preceding the survey in the 642

156 clusters.

\section{Outcome Variable}

158 Skilled birth attendant was the outcome variable for this analysis. In the EDHS data, the

159 ever-married women of reproductive age group were asked questions regarding their last

160 birth(s) that occurred in the five years preceding the survey as to who assisted them with the

161 delivery. From this specific question, dichotomous variables were created for this analysis. It 
162 was coded as 1 if the woman received assistance at delivery from skilled birth attendants

163 (SBAs) including qualified Medical Doctors (general practitioners, gynecologist or related

164 specialists), Public Health officers, Nurses, Midwiferies, or health extension workers and 0

165 otherwise

$166 Y i j=\left\{\begin{array}{c}1 \text { if mothers received assistance at delivery from } S B A \\ 0 \text { if mothers received assistance at delivery from non } S B A\end{array}\right.$

167 Where SBA is skilled birth attendant, Yij: outcome variable []ㅡ among individual i in $\mathrm{j}$ 168 cluster.

169 Independent Variables

170 Factors assumed to influence the use of SBA service utilization [3] including;

171 Sociodemographic factors: residence (urban, rural), mother's age, household wealth index,

172 mother's and father's education, mother's marital status, and mother's employment status

173 Obstetric histories: antenatal care, history of dangerous signs (history of chronic disease,

174 eclampsia and preeclampsia, bleeding, or history of abortion)

\section{Statistical analysis}

176 After extracting the EDHS data; Stata version 16.0 was used for editing, recoding, and 177 descriptive and multilevel generalized linear mixed effect model (GLMM) analysis. 178 Geographical Information System (Arc-GIS version 10.1) and Sat Scan software's were used

179 for spatial analysis. Descriptive statistics were used to summarize the overall characteristics 180 of the study participants. Because of the hierarchical nature of DHS data, multilevel GLMM 
181 was fitted with exchangeable correlation structure to identify factors associated with SBA 182 care services.

183 The data of this analysis included mothers who give birth with the five years preceding 184 survey nested within 540, 626, and 642 EAs for 2005, 2011, and 2016 EDHSs, respectively. 185 Hence, considering the hierarchical nature of the data, multilevel logistic regression models 186 were fitted to identify community and individual level factors associated with SBA by using 187 “xtmelogit" code of STATA.

188 To test the significance of the variance of random intercept, the likelihood ratio test was 189 applied. Measures of variation for random effect were determined by computing Intraclass 190 correlation coefficient (ICC), and median odds ratio (MOR). The ICC is a measure of within191 cluster variation (i.e., the variation between individuals within the same cluster) [25-27], and

192 MOR is the median odds ratio between the individual of higher propensity and the individual 193 of lower propensity when comparing two individuals from two different randomly chosen 194 clusters and it measures the unexplained cluster heterogeneity, the variation between clusters 195 by comparing two persons from two randomly chosen different clusters [27, 28]. The MOR 196 measure is always greater than or equal to 1 and if it is 1 , there is no variation between 197 clusters [29]. The within-cluster correlation was measured using ICC, which is expected to 198 be $\geq 10 \%$ to use the model.

199 The formulas for these measurements are as follows;

200 i. $\quad I C C=$ cluster level variance / total variance $:$ i.e. $I C C=\frac{v_{i}}{v_{i}+\frac{\pi^{2}}{3}}$ : were $v i=$ estimated variance in each model, which has been described elsewhere [30]. 
ii. $\quad M O R=\exp (\operatorname{sqrt}(2 * C L U S T E R$ LEVEL VARIANCE $)) * \operatorname{invnormal}(0.75))$ i.e. $M O R=\exp \left(0.95 \sqrt{v_{z}}\right)$ if $v_{z}=$ is the cluster level variance.

204 Adjusted odds ratio (AOR) with 95\% confidence interval (CI) was reported to show the

205 strength of the association and its significance for the fixed effect. Variables having p-value

$206<0.05$ were considered as having significant association with the SBA. The model goodness

207 of fit was checked and optimal model will be selected using Akaike information criterion

208 (AIC). The model with the lowest value was considered the best fit model.

\section{Spatial analysis}

210 The spatial analysis was carried out using ArcGIS 10. 1 and Sat Scan 9.6. To produce the

211 flattened map of Ethiopia, the Ethiopian Polyconic Projected Coordinate System was used

212 [31]. The units of spatial analysis were DHS clusters (geographic coordinates of EDHS were

213 collected at cluster level). The aggregated SBA count data was joined to the geographic

214 coordinates based on each EA unique identification code. To evaluate whether the pattern

215 expressed is clustered, dispersed, or random across the study areas, global spatial

216 autocorrelation was assessed with ArcGIS using the Global Moran's-I statistic (Moran’s I)

217 [32]. When p-value indicates statistical significance, a positive Moran's I index value

218 indicates tendency toward clustering, while a negative Moran's I index value indicates

219 tendency toward dispersion [33].

220 In the presence of positive global spatial autocorrelation, local spatial cluster of areas with

221 high or low SBA was detected using Kulldorff's method of purely spatial scan statistic 222 assuming the discrete Poisson probability model in SaTScan [34]. To avoid the detection of 
223 large clusters, we used a maximum of $10 \%$ of the population at risk for the spatial cluster size

224 and the analysis was done using standard Monte Carlo hypothesis testing with 999 Monte

225 Carlo replicates [35, 36]. A cluster is statistically significant when its log-likelihood ratio is

226 larger than the Standard Monte Carlo critical value (C.V) for 0.05 significance level or p-

227 value $<0.05$

228

229 Result

230 Sample characteristics and trends of skilled birth attendant

231 In three surveys (2005, 2011, and 2016), a total of 32157 pregnant mothers employed for

232 analysis. However, the data of 12 (2.2\%) clusters from 2005, 53 (8.5\%) clusters from 2011,

233 and $19(3.0 \%)$ from 2016 EDHSs were excluded from the spatial analysis as the geographical

234 information was missed.

235 The median age of mothers was 28 in 2005and 2016, and 29 in 2016. The median age at first

236 marriage was increased from 16 to 18 years. Median age at first birth was 18 (range 9-40)

237 years. Of the total, 8,503(86.23), 9,668 (82.96\%), and 8,667 (81.45\%) were rural residents in

2382005,2011 and 2016 respectively. Regarding the educational status, 7,609 (77.16\%), 8,142

239 (69.86\%), and 6,838 (64.26\%) had no formal education in 2005, 2011 and 2016 respectively.

240 Women who received ANC follow-up were increased from 28.5\% in 2005 to $62.9 \%$ in 2016.

241 Similarly, the median time of first ANC was decreased from 5 to 4 months (Tab. 1). Women

242 characteristic are summarized in Tab. 1. 
243 Tab. 1: Sample characteristics of women delivered their baby five years preceding the 2000,

$2442005,2011 \& 2016$ Survey.

245 Legends: N, total; educ., educational; Sec. ${ }^{+}$, secondary and above; $4+$, four and above

246 Institutional delivery was almost doubled (10.5\%) in 2011 and tripled (27.45\%) in 2016

247 compared to $5.92 \%$ in 2005 . The proportion of women received skilled birth delivery was

248 increased from 5.45\% (996/9862) in 2005 to $10.25 \%(1,603 / 11631)$ in 2011 and $27.5 \%$

$249(3,525 / 10641)$ in 2016. The magnitude was increased with the increased number of ANC

250 follow-up, educational level and wealth quintile. The trends of skilled birth delivery for rural

251 mothers also increased from 268 (3.15\%), to $448(4.64 \%)$ and 1,952 (22.52\%) in 2011 and

2522016 respectively (Figure 1A, 1B).

253 Figure 1:Trends of skilled birth attendant education, order of birth, wealth index and 254 maternal health service and regional states of Ethiopia.

\section{Spatial analysis of SBA utilization}

256 Spatial distribution and Autocorrelation of SBA.

257 The high proportion of skilled delivery was observed in Dire Dawa, Harari, Southern

258 Oromia, Somali, and Benishangul Gumuz regions which ranges from 61.9\% to 100\%. The

259 low proportion of skilled delivery was observed in Amhara and some parts of Oromia and

260 Tigray regions of Ethiopia. 
261 The clustered patterns of all surveys showed differences in skilled birth attendant utilization 262 occurred over the study area. Global Moran Index indicated that there is less than $1 \%$ 263 likelihood that clustered pattern could be the result of random chance. The bright red colors 264 to the end tails indicate increased significance level. All surveys indicated (Moran I (2005) $=$ 265 0.263: $\mathrm{p}<0.001,(2011)=0.175: \mathrm{p}=0.001,(2016)=0.085: \mathrm{p}<0.001)$ there was spatial 266 variability in skilled birth delivery for women in Ethiopia (Figure2A, 2B, 2C).

267 Figure 2: Spatial autocorrelation of skilled birth attendant across the regions of Ethiopia, 268 EDHS 2005, EDHS 2011, and EDHS 2016.

269 Legends: (Moran's I figure showed represents as follows A=2005, B=2011 and C=2016).

270 Spatial scan analysis

271 Totally, most likely 32 (10 for 2005, 10 for 2011, and 12 for 2016 EDHSs) significantly high

272 clusters were identified (Figure 3, figure 4, figure 5, Tab. 2). In 2005 and 2011, primary

273 and secondary clusters with high SBA were found around Addis Ababa and Dire Dawa

274 respectively. In 2016, the possible clusters with high SBA were recorded in Addis Ababa 275 (primary) and Dire Dawa and Harari (secondary) (Tab. 2).

276 Tab. 2: Identified primary and secondary clusters with high SBA Utilization, Ethiopia

277 Legends: E, east; N, North; km, kilometers; S, survey; LLR, log-likelihood ratio; RR, relative 278 ratio $; 1^{0}$, primary clusters; $2^{0}$ secondary clusters

279 Figure 3: Spatial scan statistics of skilled birth attendant across the regions of Ethiopia in 280 EDHS 2005.

281 Legend: LLR, loglikelihood ratio 
282 Figure 4: Spatial scan statistics of skilled birth attendant across the regions of Ethiopia in 283 EDHS 2011

284 Legend: LLR, loglikelihood ratio

285 Figure 5: Spatial scan statistics of skilled birth attendant across the regions of Ethiopia, in 286 EDHS 2016

287 Legend: LLR, loglikelihood ratio

288

289 Determinants of SBA utilization

290 In the mixed-effect multivariable logistic regression model; residence, women's educational

291 level, partner's educational level, age at first birth, and antenatal care were significantly

292 associated with SBA for all EDHS (2005, 2011 and 2016). However, age of women was

293 significantly associated with SBA in 2005 and 2016, whereas distance from health facilities

294 had significant association with SBA in 2011 and 2016 (Tab. 3).

295 For variables showing association in all surveys (Tab. 3), taking the most recent survey 296 (EDHS 2016), the odds of SBA were decreased by 78\% (AOR:0.22; 95\%CI:0.15, 0.32) 297 among rural residents compared to urban. The likelihood of SBA among women aged 35 298 years and above, and 20-34 years was decreased by $60 \%$ and $50 \%$ respectively, compared to 299 mothers whose age was less than 20 years. Contrary, as the age at first delivery was increased 300 by 1 year, the odds of SBA were increased by 15\% (AOR:1.06; 95\%CI:1.03, 1.08).

301 Compared to uneducated mothers, the odds of receiving SBA were higher by 54\% 302 (AOR:1.54, 95\%CI: 1.29, 1.85) for mothers completed at primary level, and three times 303 (AOR: 2.86, 95\%CI: 2.06, 3.97) for mothers completed secondary or higher educational 
304 level. Women whose partner completes secondary or higher educational level received SBA

305 twice (AOR:1.89; 95\%CI:1.46, 2.43) whose partner had no education. The odds of SBA for

306 rich women were increased by $61 \%$ (1.99 (1.53, 2.58), whereas 2.64 (AOR:2.64;

$30795 \%$ CI:1.90, 3.67) times higher among richest compared to poorest women.

308 Receiving SBA among respondents who reported that distance to a health institution is a big

309 problem was lower by $31 \%$ (AOR:0.71; 95\% CI: $0.60,0.84$ ) compared to those who reported

310 finding a health institution is not a big problem. Compared to women who never attend ANC

311 service, the likelihood of receiving SBA was increased by 2.6 (AOR:2.61; 95\%CI: 2.02,

312 3.37) for mothers who attend at most ANC visits and increased by more than four times

313 (AOR:4.32; 95\%CI: 3.34, 5.60) by attending optimal ANC (at least four times) respectively.

314 Tab. 3:Associated factors of skilled birth delivery determined by multilevel mixed effects

315 generalized linear regression (Binomial family) for 2005, 2011, and 2016 EDHS.

316 Legends: SBA, skilled birth attendant; AOR, adjusted odds ratio; hh, Household; \#, optimal

317 ANC if 4 or more visits during pregnancy; ${ }^{\circledR}$, cluster level factor; CrI, credential interval;

318 MOR, median odds ratio; CI, confidence interval; Secondary education is if one complete

319 grade 12 or more; *: <0.05, **: <0.01, ***: <0.001

320 The interclass correlation of 2016 EDHS model (ICC: 0.17, 95\%CI: 0.14, 0.22) showed

321 observations from the same cluster are usually more similar to each other than observations

322 from different clusters (Tab. 3). Thus, the cluster level random effects comprise

323 approximately $16-17 \%$ of the total residual variance in the model. In addition, the MOR

324 showed the residual heterogeneity between areas $(\mathrm{MOR}=2.72)$ was of greater relevance than

325 was the impact of the person's level of factors for understanding variations in the odds of

326 receiving a skilled birth attendant (Tab. 3). 


\section{Discussion}

329 This study amid to assess the trend, identifies the spatial distribution and determinants of

330 SBA in Ethiopia over the ten years. The delivery attended by skilled birth attendants

331 increased from $10 \%$ to $26 \%$ over the 10 years. The improvement might be due to the focus of

332 training health cadres since the inclusion of SBA as a key outcome indicator in the MDGs

333 after the 1999 International Conference on Population and Development (ICPD) [37, $\underline{\text { 38] }}$

334 based on the $2004 \mathrm{WHO} / \mathrm{FIGO} / \mathrm{ICM}$ joint statement on the definition of the skilled attendant

335 [39]. Additionally, increment in coverage of antenatal utilization and sociodemographic

336 improvement in the country might also contribute for the advancement of SBA.

337 There was a persisting spatial variation of SBA across the country as there was a significant

338 clustering in all surveys. The high magnitude of SBA was reported in urban setups whereas

339 comparatively low proportion was reported in rural parts of regions. This could be due to the

340 area with high SBA are relatively urban in which health facilities are more accessible,

341 occupied by high proportion of skilled birth attendants and women are more educated.

342 Age at interview was negatively associated with SBA. Most of the young mothers in this age

343 group had lower parity that might decrease mother's confidence and experience to deliver at

344 home. In Ethiopia, it is reported adolescent girls are more likely to visit ANC service which

345 could boost the chance of being attended by skilled birth attendant $[40, \underline{41}]$. The finding is in

346 line with reports of studies conducted in Ethiopia [느, $\underline{43}$. However, showed discrepancies

347 with the previous study conducted in Ghana as the older women had more likelihood of 
348 receiving SBA [44]. The difference comes from the higher induction and caesarean delivery

349 in former study

350 Age at first birth is positively associated with the SBA. The association might be indirectly

351 affected by education status of women during marriage, which is the most important

352 predictor of age at first birth. Education is also increasing the chance of readiness that related

353 to birth preparedness and complications [45]. Hence, being pregnant for the first time

354 increase the chance of birth preparedness including choice of birth attendant.

355 The SBA was higher by two to three times among higher quintiles of wealth index compared

356 to the poorest ones. The result is similar with the association reported in Bangladesh [46],

357 South Sudan [47], and India [48]. the study conducted in 2013-2014 in Malawi also reported

358 usage for health services was lowest among women belonging to the lowest wealth quintile

359 [49]. Similarly, the local study in Ethiopia [50] also reported the high income level is

360 positively associated with the SBA. Even though the institutional delivery is free of charge in

361 Ethiopia, wealth might be determining the other fees charged for required drugs and supplies

362 that poorest mothers did not afford.

363 The likelihood of SBA for rural residents was decreased by $70 \%$ to $83 \%$ compared to the

364 urban. This might be due to the socioeconomic inequalities, access to health information, and

365 differences in health services access (antenatal care or institutional delivery) between urban

366 and rural settings in the country. The result was comparable with studies conducted in

367 Malawi [49], Bangladesh [46], and Malawi [49]. 
368 Both mothers and their partner's educational level were positively associated with SBA

369 persistently in all surveys. Receiving SBA was higher by more than fifty percent for mothers

370 completed primary and three times for mothers with secondary or higher educational level.

371 Educated mothers had the control over resources within the household, more open and better

372 communication with the husband, more decision-making power, increased self-worth, better

373 coping abilities, and negotiating skills as well as reduced power differential towards health

374 care providers and thus better communication and ability to demand adequate services [51].

375 The previous studies conducted in Namibia [52], Bangladesh [46], Malawi [49], and South

376 Sudan [47] also support similar view.

377 The SBA was $10 \%$ to $89 \%$ higher among women whose partner was completed at primary

378 and secondary or post-secondary educational level compared to women whose partner was

379 no formal education. A study conducted in Kenya [ 53 , 54] and analysis from Kenya's KDHS

380 2008-09 [55]. It is believed that educated husbands are better understand the benefits of SBA,

381 had better attitudes and cultural beliefs. It is also hypothesized that educated person is more

382 likely to seek skilled care and higher interest to new health-related information.

383 Positive association was observed between SBA and number of ANC follow-up. The trend of

384 skilled birth attendant over the last ten years was increased with the increment of optimal

385 (four or more times) antenatal care utilization. Antenatal care is empowering mothers by

386 exposing them to the health information benefit of institutional delivery of postnatal care.

387 Moreover, women receive the identification of preexisting health conditions, early detection

388 of complications arising during pregnancy, and birth preparedness and complication planning 
389 which expose them to skilled birth attendants [56]. The finding is in agreement with studies

390 conducted in Bangladesh [46] and South Sudan [47].

391 In 2005 EDHS, the distance from health facilities was not associated with SBA. However, it

392 was negatively associated with SBA in 2011 and 2016 EDHS. Women who reported the

393 distance from health facilities is big problem were 29\% (2016 EDHS) to 31\% (2011 EDHS)

394 less likely to receive SBA. The discrepancy might be originated from the difference in health

395 service coverage over the past years. Before 2000, most part of the country (Ethiopia) had

396 low coverage where all women share the same problem whereas the improvement in primary

397 health coverage along with frontline health extension workers [57]. This might be giving

398 privilege to the urban and semiurban areas. The finding is also in agreement with studies

399 conducted in North Gondar [58] and South West Shewa [59], Ethiopia, and in Bangladesh 400 [60].

\section{Strength and limitations}

402 Our model results affirm the strong methodological gains of spatial and advanced models for 403 national estimation of SBA utilization and its determinants. The description of ten-year 404 trends of SBA is another strength of this analysis.

405 Despite our extensive and systematic efforts to diagnose and improve the models, the study is 406 not without limitations. First, removing DHS clusters without geographic coordinate

407 information might under or overestimate the study finding. The second limitation was the 408 location of data values was displaced up to 2 kilometers for urban and up to 5 kilometers for

409 rural areas to ensure respondent confidentiality, thus, this was the challenge to know the 
410 exact cases' location. Another limitation was small samples from Somali region in 2005 and

4112011 might be affect the result of the region because DHS does not provide distinct weights

412 for different levels, such as region, cluster or household-level weights.

\section{Conclusion}

414 The SBA utilization has shown a substantial increase over time from 2005 to 2016. Skilled

415 birth attendant utilization showed spatial variation in Ethiopia. We recommend strengthening

416 maternal health programs with special emphasis for uneducated and women from rural parts

417 of a country. There is also need for more national studies highlighting the regional disparities

418 in maternal healthcare service utilization.

420 Abbreviation

421 ANC: Antenatal care

422 CSA: Central Statistical Agency

423 DHS: Demographic and health survey

424 EDHS: Ethiopian Demographic and Health Survey

425 GLMM: Generalized Linear Mixed Effect Model

426 MOH: Ministry of Health

427 SBA: Skilled Birth Attendance 
428 SGD: Sustainable Development Goal

429 WHO: World Health Organization

430 Declarations

431 Ethics approval and consent to participate

432 This study use the secondary data from the DHS repository and does not require ethical

433 approval.

434 Consent for publication

435 Not applicable

436 Availability of data and materials

437 The datasets generated and/or analysed during the current study are available in the

438 https://dhsprogram.com/data/available-datasets.cfm repository. Additionally, all data

439 generated or analysed during this analysis will be found from the corresponding author upon

440 request.

441 Competing interests

442 The authors declare that they have no competing interests.

\section{$443 \quad$ Funding}


444 No fund was received for the designing of the study, analysis, and interpretation of data and

445 in writing the manuscript.

446 Authors' contributions

447 LDR conceptualize this study and major contributors in designing data acquisition, analysis,

448 and interpretation. The other authors (AT, BST and ABW) were drafting and revising the

449 article for intellectual content. All authors read and approved the final manuscript.

\section{Acknowledgements}

451 We would like to acknowledge the DHS program for allowing us access to the data to

452 perform this study.

\section{Reference}

454 1. Demographic EEIIC, Maryland, USA. Health survey 2011, central statistical agency, Addis Ababa. 2012.

2. Demographic E, Ethiopia ICF International Calverton, Maryland, USA. Health survey 2017 central statistical agency Addis Ababa. 2018.

3. Stensballe LG, Ravn H, Birk NM, Kjaergaard J, Nissen TN, Pihl GT, et al. BCG Vaccination at Birth and Rate of Hospitalization for Infection Until 15 Months of Age in Danish Children: A Randomized Clinical Multicenter Trial. Journal of the Pediatric Infectious Diseases Society. 2019;8(3):213-20.

4. Demographic E, Ethiopia ICF International Calverton, Maryland, USA. Health survey 2000 central statistical agency Addis Ababa. 2001.

5. Lim SS, Allen K, Bhutta ZA, Dandona L, Forouzanfar MH, Fullman N, et al. Measuring the health-related Sustainable Development Goals in 188 countries: a baseline analysis from the Global Burden of Disease Study 2015. The Lancet. 2016;388(10053):1813-50.

6. Team S. Monitoring the Progress of Sustainable Development Goals in Madhya Pradesh. 2018.

7. Sives K. Maternal health as a human right: health care system innovations to reduce inequities in maternal health in Bolivia, Nicaragua and Guatemala 1990-2018. 2018.

8. Dang V, Do T, Nguyen C, Phung T, Phung T. Achievements and challenges in the progress of reaching millennium development goals of Vietnam. 2013. 
9. Wahlström S, Björklund M, Munck B. The Professional Role of Skilled Birth Attendants' in Nepal-A Phenomenographic Study. Sexual \& Reproductive Healthcare. 2019.

10. van den Broek NR. Maternal and newborn health. Hunter's Tropical Medicine and Emerging Infectious Diseases: Elsevier; 2020. p. 133-40.

11. Mohamed SY. Determinants of access to skilled birth attendants by women in Galkacyo district, Somalia. 2018.

12. Alemayehu M, Mekonnen W. The Prevalence of Skilled Birth Attendant Utilization and Its Correlates in North West Ethiopia. Biomed Res Int. 2015;2015:436938.

13. Kebe Y. The role of the midwife. Afr Health. 1994;16(6):13-4.

14. Ayele GS, Melku AT, Belda SS. Utilization of skilled birth attendant at birth and associated factors among women who gave birth in the last 24 months preceding the survey in Gura Dhamole Woreda, Bale zone, southeast Ethiopia. BMC Public Health. 2019;19(1):1501.

15. Worku AG, Yalew AW, Afework MF. Factors affecting utilization of skilled maternal care in Northwest Ethiopia: a multilevel analysis. BMC international health and human rights. 2013;13(1):20.

16. Bobo FT, Yesuf EA, Woldie MJIjfeih. Inequities in utilization of reproductive and maternal health services in Ethiopia. 2017;16(1):105.

17. Banke-Thomas OE, Banke-Thomas AO, Ameh CAJBp, childbirth. Factors influencing utilisation of maternal health services by adolescent mothers in Low-and middle-income countries: a systematic review. 2017;17(1):65.

18. Umar AS. Use of maternal health services and pregnancy outcomes in Nigeria. 2016.

19. CSA Central Statistical Agency, ICF. Ethiopia Demographic and Health Survey 2016. Addis Ababa, Ethiopia, and Rockville, Maryland, USA: CSA and ICF; 2017.

20. CSA. Human population census of Ethiopia 2007. In: Ethiopia CSAo, editor. Addis Ababa, Ethiopia2007.

21. Central Statistical Agency [Ethiopia] and ICF International. Ethiopia Demographic and Health Survey 2011. 2012, Addis Ababa, Ethiopia and Calverton, Maryland, USA: Central Statistical Agency and ICF International.

22. Central Statistical Agency [Ethiopia] and ICF International. Ethiopia Demographic and Health Survey 2016. 2018, Addis Ababa, Ethiopia and Calverton, Maryland, USA: Central Statistical Agency and ICF International.

23. Central Statistical Agency [Ethiopia] and ICF International. Ethiopia Demographic and Health Survey 2005. 2006, Addis Ababa, Ethiopia and Calverton, Maryland, USA: Central Statistical Agency and ICF International.

24. Central Statistical Agency [Ethiopia] and ICF International. Ethiopia Demographic and Health Survey 2000. 2001, Addis Ababa, Ethiopia and Calverton, Maryland, USA: Central Statistical Agency and ICF International.

25. Stanish WM, Taylor NJTAS. Estimation of the intraclass correlation coefficient for the analysis of covariance model. 1983;37(3):221-4.

26. Nichols DPJSk. Choosing an intraclass correlation coefficient. 1998;67:1-2.

27. Merlo J, Chaix B, Ohlsson H, Beckman A, Johnell K, Hjerpe P, et al. A brief conceptual tutorial of multilevel analysis in social epidemiology: using measures of 
28. Siegmunt O. Intraclass Correlation, Median Odds Ratio, and Ecological Reliability. Neighborhood Disorganization and Social Control: Springer; 2016. p. 43-5.

29. Merlo J, Wagner P, Ghith N, Leckie G. An Original Stepwise Multilevel Logistic Regression Analysis of Discriminatory Accuracy: The Case of Neighbourhoods and Health. PLoS One. 2016;11(4):e0153778.

30. Tom A, Bosker TASRJ, Bosker RJ. Multilevel analysis: an introduction to basic and advanced multilevel modeling: Sage; 1999.

31. Tegegne TK, Chojenta C, Getachew T, Smith R, Loxton DJPo. Service environment link and false discovery rate correction: Methodological considerations in population and health facility surveys. 2019;14(7).

32. Anselin L. Local indicators of spatial association-LISA. Geographical analysis. 1995;27(2):93-115.

33. Fischer MM, Getis A. Handbook of applied spatial analysis: software tools, methods and applications: Springer Science \& Business Media; 2009.

34. Boscoe FP, McLaughlin C, Schymura MJ, Kielb CLJH, Place. Visualization of the spatial scan statistic using nested circles. 2003;9(3):273-7.

35. Besag J, Clifford PJB. Generalized monte carlo significance tests. 1989;76(4):633-42.

36. Gentle JE. Random number generation and Monte Carlo methods: Springer Science \& Business Media; 2006.

37. Gaffey MF, Das JK, Bhutta ZA. Millennium Development Goals 4 and 5: Past and future progress. Seminars in fetal \& neonatal medicine. 2015;20(5):285-92.

38. Lozano R, Wang H, Foreman KJ, Rajaratnam JK, Naghavi M, Marcus JR, et al. Progress towards Millennium Development Goals 4 and 5 on maternal and child mortality: an updated systematic analysis. Lancet (London, England). 2011;378(9797):1139-65.

39. World Health O. Making pregnancy safer: the critical role of the skilled attendant: a joint statement by WHO, ICM and FIGO: World health organization; 2004.

40. Bhandari TR, Dangal G. Safe delivery care: policy, practice and gaps in Nepal. JNMA; journal of the Nepal Medical Association. 2013;52(192):637-44.

41. Wilunda C, Quaglio G, Putoto G, Takahashi R, Calia F, Abebe D, et al. Determinants of utilisation of antenatal care and skilled birth attendant at delivery in South West Shoa Zone, Ethiopia: a cross sectional study. Reprod Health. 2015;12:74.

42. Ababulgu FA, Bekuma TT. Delivery Site Preferences and Associated Factors among Married Women of Child Bearing Age in Bench Maji Zone, Ethiopia. Ethiop J Health Sci. 2016;26(1):45-54.

43. Tesfaw N, Gizachew A, Kassa GM, Abajobir AA. Skilled Delivery Service Utilization and Associated Factors among Mothers Who Gave Birth in the Last Two Years in Northwest Ethiopia. Ethiop J Health Sci. 2018;28(4):423-32.

44. Manyeh AK, Akpakli DE, Kukula V, Ekey RA, Narh-Bana S, Adjei A, et al. Sociodemographic determinants of skilled birth attendant at delivery in rural southern Ghana. BMC research notes. 2017;10(1):268. 
603

604

605
45. Basso O, Weinberg CR, D'Aloisio AA, Sandler DP. Maternal age at birth and daughters' subsequent childlessness. Human reproduction (Oxford, England). 2018;33(2):311-9.

46. Kibria GMA, Burrowes V, Choudhury A, Sharmeen A, Ghosh S, Kalbarczyk A. A comparison of practices, distributions and determinants of birth attendance in two divisions with highest and lowest skilled delivery attendance in Bangladesh. BMC pregnancy and childbirth. 2018;18(1):122.

47. Mugo NS, Agho KE, Dibley MJ. Risk Factors for Non-use of Skilled Birth Attendants: Analysis of South Sudan Household Survey, 2010. Maternal and child health journal. 2016;20(6):1266-79.

48. Roy MP, Mohan U, Singh SK, Singh VK, Srivastava AK. Factors associated with the preference for delivery at the government hospitals in rural areas of Lucknow district in Uttar Pradesh. Indian journal of public health. 2013;57(4):268.

49. Yaya S, Bishwajit G, Shah V. Wealth, education and urban-rural inequality and maternal healthcare service usage in Malawi. BMJ global health. 2016;1(2):e000085.

50. Dufera A, Bala ET, Desta HO, Taye K. Determinants of Skilled Birth Attendant Utilization at Chelia District, West Ethiopia. International journal of reproductive medicine. 2020;2020:9861096.

51. Carter MW, Speizer I. Salvadoran fathers' attendance at prenatal care, delivery, and postpartum care. Revista panamericana de salud publica $=$ Pan American journal of public health. 2005;18(3):149-56.

52. Zere E, Oluwole D, Kirigia JM, Mwikisa CN, Mbeeli T. Inequities in skilled attendance at birth in Namibia: a decomposition analysis. BMC pregnancy and childbirth. 2011;11:34.

53. Nanjala M, Wamalwa D. Determinants of male partner involvement in promoting deliveries by skilled attendants in Busia, Kenya. Global journal of health science. 2012;4(2):60-7.

54. Gitimu A, Herr C, Oruko H, Karijo E, Gichuki R, Ofware P, et al. Determinants of use of skilled birth attendant at delivery in Makueni, Kenya: a cross sectional study. BMC pregnancy and childbirth. 2015;15:9.

55. Mangeni JN, Mwangi A, Mbugua S, Mukthar VK. MALE INVOLVEMENT IN MATERNAL HEALTHCARE AS A DETERMINANT OF UTILISATION OF SKILLED BIRTH ATTENDANTS IN KENYA. East African medical journal. 2012;89(11):372-83.

56. Lincetto O, Mothebesoane-Anoh S, Gomez P, Munjanja S. Antenatal care. Opportunities for Africa's newborns: Practical data, policy and programmatic support for newborn care in Africa. 2006:55-62.

57. Eregata GT, Hailu A, Memirie ST, Norheim OF. Measuring progress towards universal health coverage: national and subnational analysis in Ethiopia. BMJ global health. 2019;4(6).

58. Alemayehu M, Mekonnen W. The prevalence of skilled birth attendant utilization and its correlates in North West Ethiopia. BioMed research international. 2015;2015.

59. Wilunda C, Quaglio G, Putoto G, Takahashi R, Calia F, Abebe D, et al. Determinants of utilisation of antenatal care and skilled birth attendant at delivery in South West Shoa Zone, Ethiopia: a cross sectional study. Reproductive health. 2015;12(1):1-12. 
606 60. Anwar I, Sami M, Akhtar N, Chowdhury ME, Salma U, Rahman M, et al. Inequity in maternal health-care services: evidence from home-based skilled-birth-attendant

$$
9 .
$$




\begin{tabular}{|c|c|c|c|c|c|c|c|}
\hline & 1 & $1,548(15.7)$ & $2,925(25.1)$ & $2,678(25.2)$ & $236(23.0)$ & $636(39.6)$ & $1,256(35.6)$ \\
\hline & 2 & $704(7.1)$ & $582(5.0)$ & $1,125(10.5)$ & $475(46.4)$ & $461(28.8)$ & $931(26.4)$ \\
\hline \multirow{4}{*}{$\begin{array}{l}\text { Educatio } \\
\text { nal level } \\
\text { of } \\
\text { partner }\end{array}$} & $\mathbf{N}$ & $\mathbf{9 , 7 5 7}$ & 11,418 & 9,933 & 1003 & 1553 & 3201 \\
\hline & No educ. & $5,834(59.8)$ & $5,964(52.2)$ & $4,928(49.6)$ & $183(18.3)$ & $279(18.0)$ & $913(28.5)$ \\
\hline & Primary & $2,538(26.0)$ & 4,177 (36.6) & $3,220(32.4)$ & $219(21.8)$ & $618(39.8)$ & $1,078(33.7)$ \\
\hline & Sec. $^{+}$ & $1,385(14.2)$ & $1,277(11.2)$ & $1,785(18.0)$ & $601(59.9)$ & $656(42.2)$ & $1,210(37.8)$ \\
\hline Problem- & $\mathbf{N}$ & 9,861 & 11,631 & 10,641 & 1025 & 1603 & 3,525 \\
\hline Health & Big & $6,942(70.4)$ & $8,594(73.9)$ & $5,834(54.8)$ & $372(36.3)$ & $662(41.3)$ & $1,235(35.0)$ \\
\hline \multirow[t]{3}{*}{ access } & Small & 2,919 (29.6) & $3,037(26.1)$ & $4,807(45.2)$ & $653(63.7)$ & 941 (58.7) & $2,290(65.0)$ \\
\hline & Later & 1,649 (16.7) & $2,099(18.1)$ & $1,491(14.0)$ & $189(18.4)$ & $322(20.1)$ & 559 (15.9) \\
\hline & No more & $1,571(15.9)$ & $951(8.2)$ & $661(6.2)$ & $195(19.0)$ & $143(8.9)$ & $205(5.82)$ \\
\hline \multirow[t]{3}{*}{ Residence } & $\mathbf{N}$ & 9,861 & 11,631 & 10,641 & 1025 & 1,603 & 3,525 \\
\hline & Urban & $1,358(13.8)$ & $1,985(17.1)$ & $1,974(18.6)$ & 733 (71.5) & $1,155(72.1)$ & $1,573(44.6)$ \\
\hline & Rural & $8,503(86.2)$ & $9,646(82.9)$ & $8,667(81.5)$ & $292(28.5)$ & 448 (27.9) & $1,952(55.4)$ \\
\hline wealth & & 9,861 & 11,631 & 10,641 & 1025 & 1603 & 3525 \\
\hline \multirow[t]{5}{*}{ Index } & Poorest & $2,529(25.7)$ & $3,620(31.1)$ & $3,993(37.5)$ & $49(4.8)$ & $113(7.1)$ & $509(14.4)$ \\
\hline & Poorer & $1,846(18.7)$ & $2,107(18.1)$ & $1,782(16.8)$ & $27(2.6)$ & $76(4.7)$ & $469(13.3)$ \\
\hline & Middle & $1,837(18.6)$ & $1,863(16.0)$ & $1,466(13.8)$ & $53(5.7)$ & $74(4.6)$ & $432(12.3)$ \\
\hline & Richer & $1,672(17.0)$ & $1,869(16.1)$ & $1,308(12.3)$ & $91(8.89)$ & $164(10.2)$ & $463(13.1)$ \\
\hline & Richest & $1,977(20.1)$ & $2,172(18.7)$ & $2,092(19.7)$ & $805(78.5)$ & $1,176(73.4)$ & $1,652(46.9)$ \\
\hline \multicolumn{2}{|l|}{ Sex of } & $\mathbf{9 , 8 6 1}$ & 11,631 & 10,641 & 1025 & 1,603 & 3,525 \\
\hline \multirow[t]{2}{*}{ HH head } & Male & $8,527(86.5)$ & $9,448(81.2)$ & $8,383(78.8)$ & $762(74.3)$ & $1,165(72.7)$ & $2,681(76.1)$ \\
\hline & Female & $1,334(13.5)$ & $2,183(18.8)$ & $2,258(21.2)$ & $263(25.7)$ & $438(27.3)$ & $844(23.9)$ \\
\hline \multirow[t]{5}{*}{ Age } & & 9861 & 11631 & 10641 & 1025 & 1603 & 3525 \\
\hline & Less than & $533(5.4)$ & $514(4.4)$ & $404(3.8)$ & $63(6.2)$ & $67(4.2)$ & $178(5.1)$ \\
\hline & 20 & & & & & & \\
\hline & $20-34$ & $6,899(70.0)$ & $8,336(71.7)$ & $7,692(72.3)$ & $792(77.3)$ & $1,293(80.7)$ & $2,634(74.7)$ \\
\hline & $\begin{array}{l}35 \text { and } \\
\text { above }\end{array}$ & $2,429(24.6)$ & $2,781(23.9)$ & $2,545(23.9)$ & $170(16.6)$ & $243(15.2)$ & $713(20.2)$ \\
\hline
\end{tabular}




\begin{tabular}{llllllll}
\hline Terminat & N & $\mathbf{9 , 8 6 1}$ & $\mathbf{1 1 , 6 3 1}$ & $\mathbf{1 0 , 6 4 1}$ & $\mathbf{1 0 2 5}$ & $\mathbf{1 , 6 0 3}$ & $\mathbf{3 , 5 2 5}$ \\
$\mathbf{e}$ & No & $9,148(92.8)$ & 10,467 & $9,736(91.5)$ & $925(90.2)$ & $1,428(89.1)$ & $3,211(91.1)$ \\
pregnanc & & & $(90.0)$ & & & & \\
$\mathbf{y}$ & Yes & $713(7.2)$ & $1,164(10.0)$ & $905(8.5)$ & $100(9.8)$ & $175(10.9)$ & $314(8.9)$ \\
\hline
\end{tabular}

620

621 Table 2: Identified primary and secondary clusters with high SBA Utilization, Ethiopia.

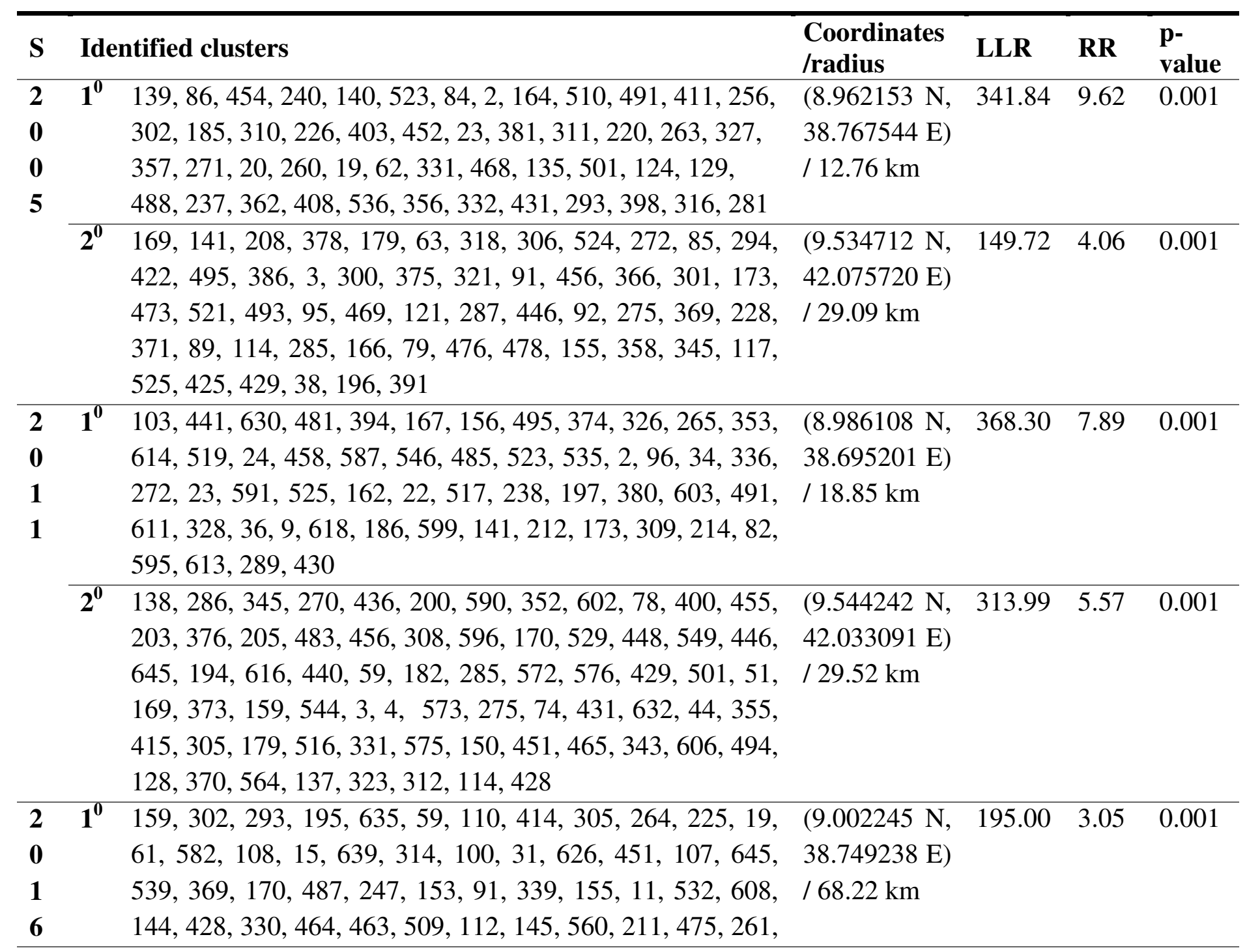


$274,287,252,402,90,236,83,353,147,303,40,290$,

125

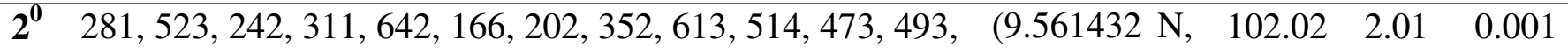
$27,444,185,519,471,224,385,5,535,390,606,273$, $631,151,74,111,467,380,363,282,190,644,610,30, \quad 42.037215 \mathrm{E})$ 5

$101,140,43,546,381,495,288,329,383,238,419,357$, $443,173,396,60,393,594,614,28,228,157,397,56$, / $32.89 \mathrm{~km}$ $387,257,534,44,179,607,321,58,29,194,418,240,25$, $500,587,115,133,483,580,557$

622

623 Table 3: Determinants of skilled birth attendant determined by multilevel mixed effects 624 generalized linear regression (Binomial family) for 2005, 2011 and 2016 EDHS.

\begin{tabular}{lllc}
\hline \multicolumn{1}{c}{ SBA } & \multicolumn{1}{c}{2005} & \multicolumn{1}{c}{2011} & \multicolumn{1}{c}{2016} \\
\hline \multicolumn{1}{c}{ AORe category (years) } & \multicolumn{1}{c}{ AOR $(95 \mathrm{Cl})$} & AOR $(95 \mathrm{Cl})$ \\
$15-19$ & 1 & & \\
$20-34$ & $0.57(0.36,0.89)^{*}$ & $0.99(0.64,1.53)$ & 1 \\
35 and above & $0.40(0.24,0.68)^{* *}$ & $0.74(0.45,1.20)$ & $0.50(0.36,0.70)^{* * *}$ \\
Region ${ }^{*}$ & & & $0.43(0.30,0.62)^{* * *}$ \\
Addis Ababa & 1 & 1 & \\
Tigray & $0.25(0.12,0.51)^{* * *}$ & $0.15(0.08,0.29)^{* * *}$ & $0.92(0.39,2.19)$ \\
Afar & $0.30(0.12,0.75)^{*}$ & $0.15(0.07,0.31)^{* * *}$ & $0.12(0.05,0.31)^{* * *}$ \\
Amhara & $0.23(0.12,0.45)^{* * *}$ & $0.30,(0.16,0.57)^{* * *}$ & $0.18(0.08,0.43)^{* * *}$ \\
Oromia & $0.37(0.20,0.68)^{* *}$ & $0.26(0.14,0.47)^{* * *}$ & $0.23(0.10,0.54)^{* *}$ \\
Somali & $0.34(0.13,0.91)^{*}$ & $0.32(0.15,0.65)^{* *}$ & $0.21(0.09,0.51)^{* * *}$ \\
Ben-Gumuz & $0.46(0.22,0.98)^{*}$ & $0.42(0.22,0.83)^{*}$ & $0.283(0.12,0.68)^{* *}$ \\
SNNP & $0.19(0.10,0.36)^{* * *}$ & $0.21(0.11,0.42)^{* * *}$ & $0.32(0.13,0.76)^{*}$ \\
Gambela & $0.96(0.48,1.93)$ & $0.66(0.34,1.30)$ & $0.25(0.10,0.61)^{* *}$ \\
Harari & $1.11(0.56,2.18)$ & $0.86(0.45,1.63)$ & $0.46(0.19,1.13)$ \\
\hline
\end{tabular}




\begin{tabular}{|c|c|c|c|}
\hline Dire Dawa & $0.67(0.34,1.31)$ & $1.43(0.76,2.72)$ & $0.45(0.180,1.11)$ \\
\hline \multicolumn{4}{|l|}{ Residence @ } \\
\hline Urban & 1 & 1 & 1 \\
\hline Rural & $0.29(0.19,0.46) * * *$ & $0.17(0.12,0.26) * * *$ & $0.22(0.15,0.32) * * *$ \\
\hline \multicolumn{4}{|l|}{ Educational Level } \\
\hline No education & 1 & 1 & 1 \\
\hline Primary & $1.50(1.10,2.03) * *$ & $1.77(1.41,2.22) * * *$ & $1.54(1.29,1.85) * * *$ \\
\hline$\geq$ Secondary & $2.50(1.72,3.63) * * *$ & $4.14(2.78,6.15) * * *$ & $2.86(2.06,3.97) * * *$ \\
\hline \multicolumn{4}{|c|}{ Partner's Educational level } \\
\hline No education & 1 & 1 & 1 \\
\hline Primary & $1.39(1.00,1.92)$ & $1.41(1.11,1.80) * *$ & $1.10(0.92,1.31)$ \\
\hline$\geq$ Secondary & $2.09(1.47,2.99) * * *$ & $2.19(1.59,3.0) * * *$ & $1.89(1.46,2.43) * * *$ \\
\hline \multicolumn{4}{|l|}{ Head of hh } \\
\hline Male & 1 & 1 & 1 \\
\hline Female & $1.19(0.88,1.59)$ & $1.22(0.97,1.54)$ & $1.15(0.94,1.42)$ \\
\hline Age at first birth & $1.11(1.07,1.14) * * *$ & $1.06(1.04,1.09) * * *$ & $1.06(1.03,1.08) * * *$ \\
\hline \multicolumn{4}{|c|}{ History of Abortion } \\
\hline No & 1 & 1 & 1 \\
\hline Yes & $1.29(0.83,2.01)$ & $1.26(0.92,1.73)$ & $1.00(0.78,1.29)$ \\
\hline \multicolumn{4}{|l|}{ ANC follow up } \\
\hline No & 1 & 1 & 1 \\
\hline Sub optimal & $3.20(2.30,4.45) * * *$ & $2.61(2.02,3.37) *$ & $2.61(2.02,3.37) * * *$ \\
\hline Optimal ${ }^{\#}$ & $5.67(4.18,7.70) * * *$ & $4.32(3.34,5.60) * * *$ & $4.32(3.34,5.60) * * *$ \\
\hline \multicolumn{4}{|l|}{ Wealth index } \\
\hline Poorest & 1 & 1 & 1 \\
\hline Poor & $0.82(0.44,1.54)$ & $1.14(0.76,1.71)$ & $1.88(1.49,2.38) * * *$ \\
\hline Middle & $1.20(0.66,2.18)$ & $1.02(0.67,1.54)$ & $1.72(1.34,2.20) * * *$ \\
\hline Rich & $2.10(1.23,3.59) * *$ & $1.61(1.11,2.35)^{*}$ & $1.99(1.53,2.58) * * *$ \\
\hline
\end{tabular}




\begin{tabular}{|c|c|c|c|}
\hline Richest & $3.52(2.02,6.14) * * *$ & $2.35(1.54,3.60) * * *$ & $2.64(1.90,3.67) * * *$ \\
\hline \multicolumn{4}{|c|}{ Distance from health facility } \\
\hline Small problem & 1 & 1 & 1 \\
\hline Big problem & $0.83(0.66,1.11)$ & $0.69(0.56,0.86) * * *$ & $0.71(0.60,0.84) * * *$ \\
\hline \multicolumn{4}{|c|}{ Model summary } \\
\hline ICC & $0.16(0.12,0.24)$ & $0.17(0.13,0.24)$ & $0.17(0.14,0.22)$ \\
\hline MOR (95\% Crl) & $2.70(1.80,3.64)$ & $2.72(2.47,2.98)$ & $2.72(1.92,3.52)$ \\
\hline AIC & 2363.69 & 1440.17 & 1392.79 \\
\hline \multicolumn{4}{|c|}{$\begin{array}{l}\text { SBA, skilled birth attendant; AOR, adjusted odds ratio; hh, Household; }{ }^{*} \text {, optimal ANC if } 4 \text { or more visit } \\
\text { during pregnancy; } @ \text {, cluster level factor; Crl, credential interval; MOR, median odds ratio; } \mathrm{Cl} \text {, } \\
\text { confidence interval; Secondary education is if one complete grade } 12 \text { or more, } \\
*:<0.05, * *:<0.01, * * *:<0.001\end{array}$} \\
\hline
\end{tabular}


Figures

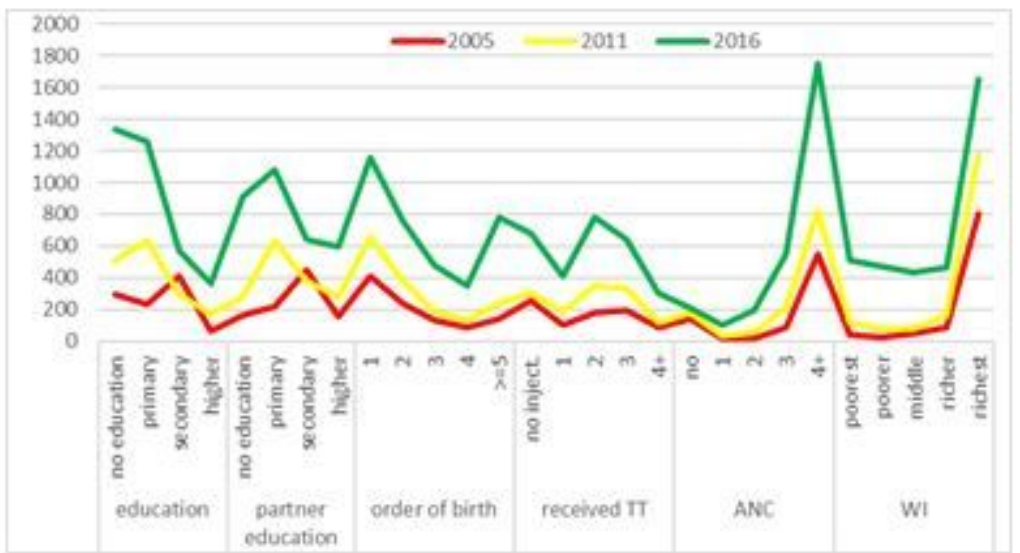

A

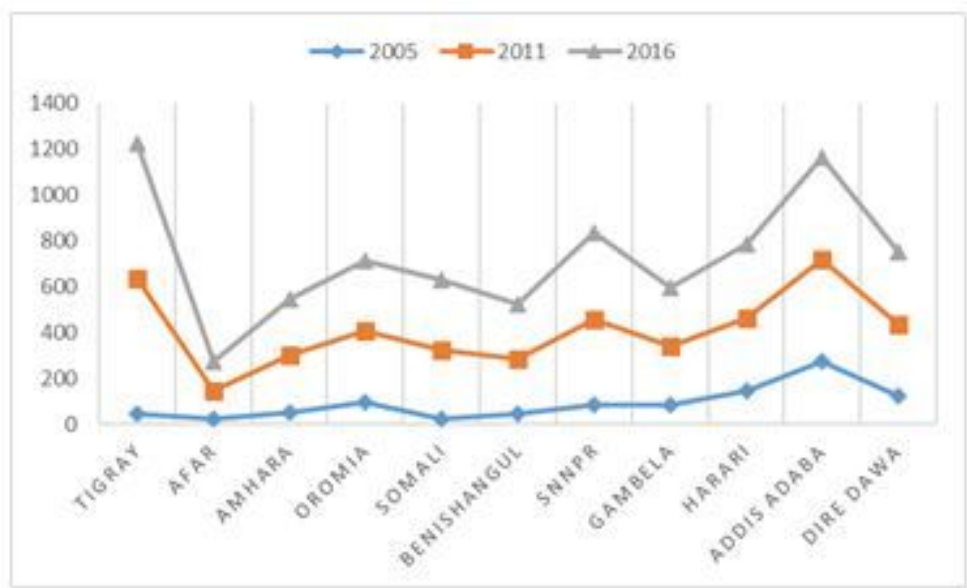

\section{Figure 1}

Trends of skilled birth attendant education, order of birth, wealth index and maternal health service and regional states of Ethiopia. 


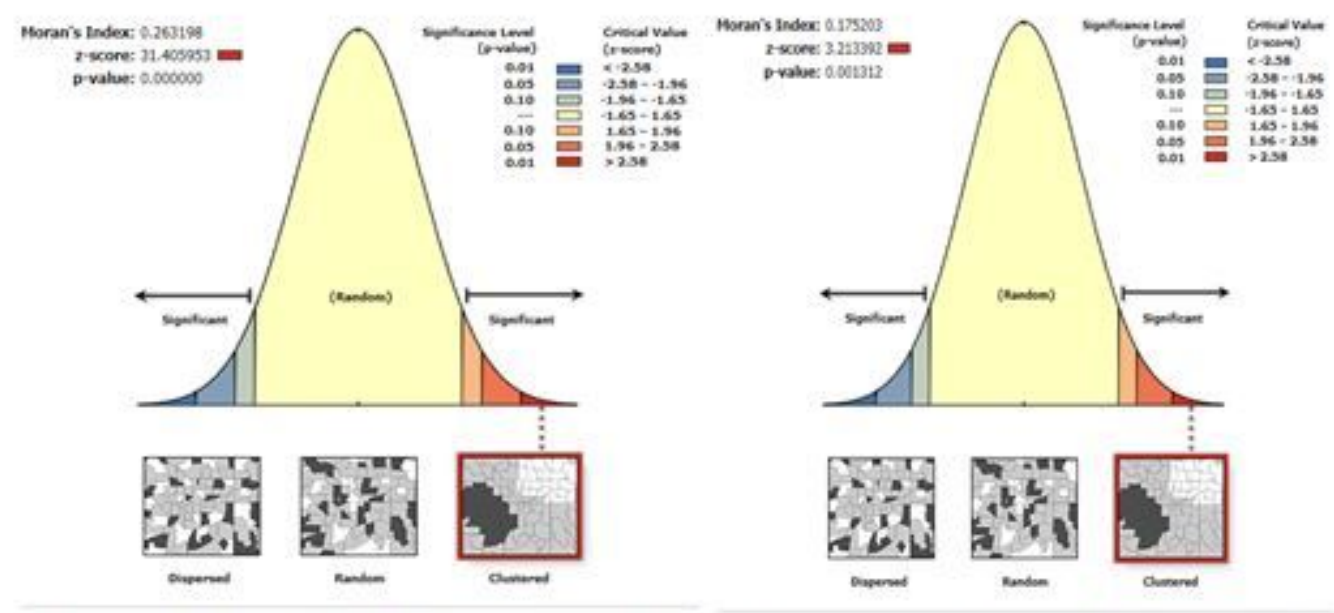

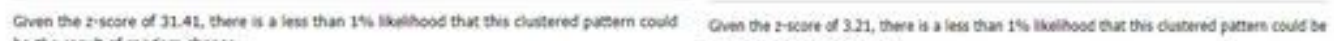
be the resole of random chance.

A

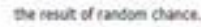

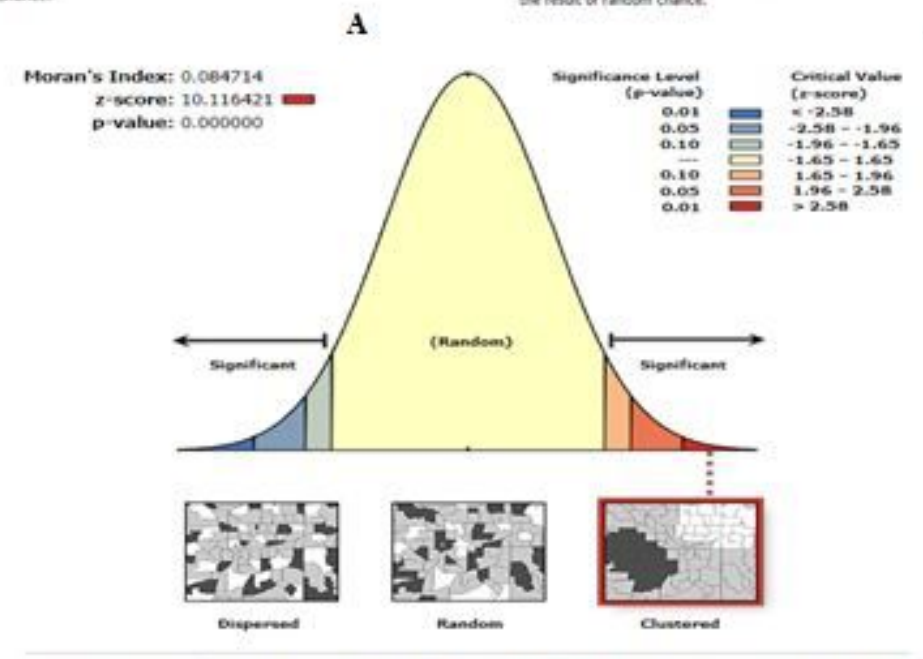

C

Given the z-score of 10.12 , there is a less than $1 \%$ lakethood that this clustered pattern could be the result of random chance.

\section{Figure 2}

Spatial autocorrelation of skilled birth attendant across the regions of Ethiopia, EDHS 2005, EDHS 2011, and EDHS 2016. 


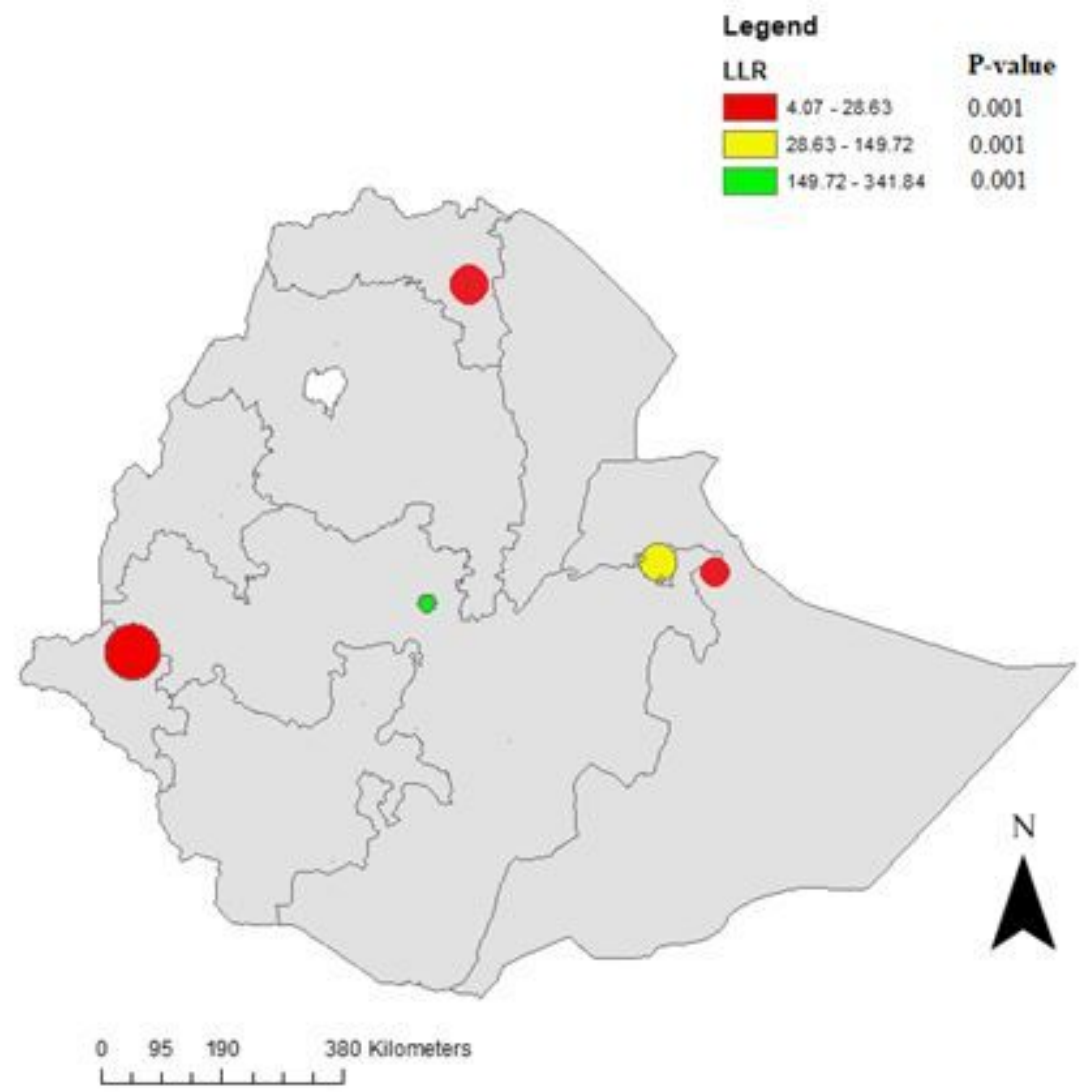

Figure 3

Spatial scan statistics of skilled birth attendant across the regions of Ethiopia in EDHS 2005. 


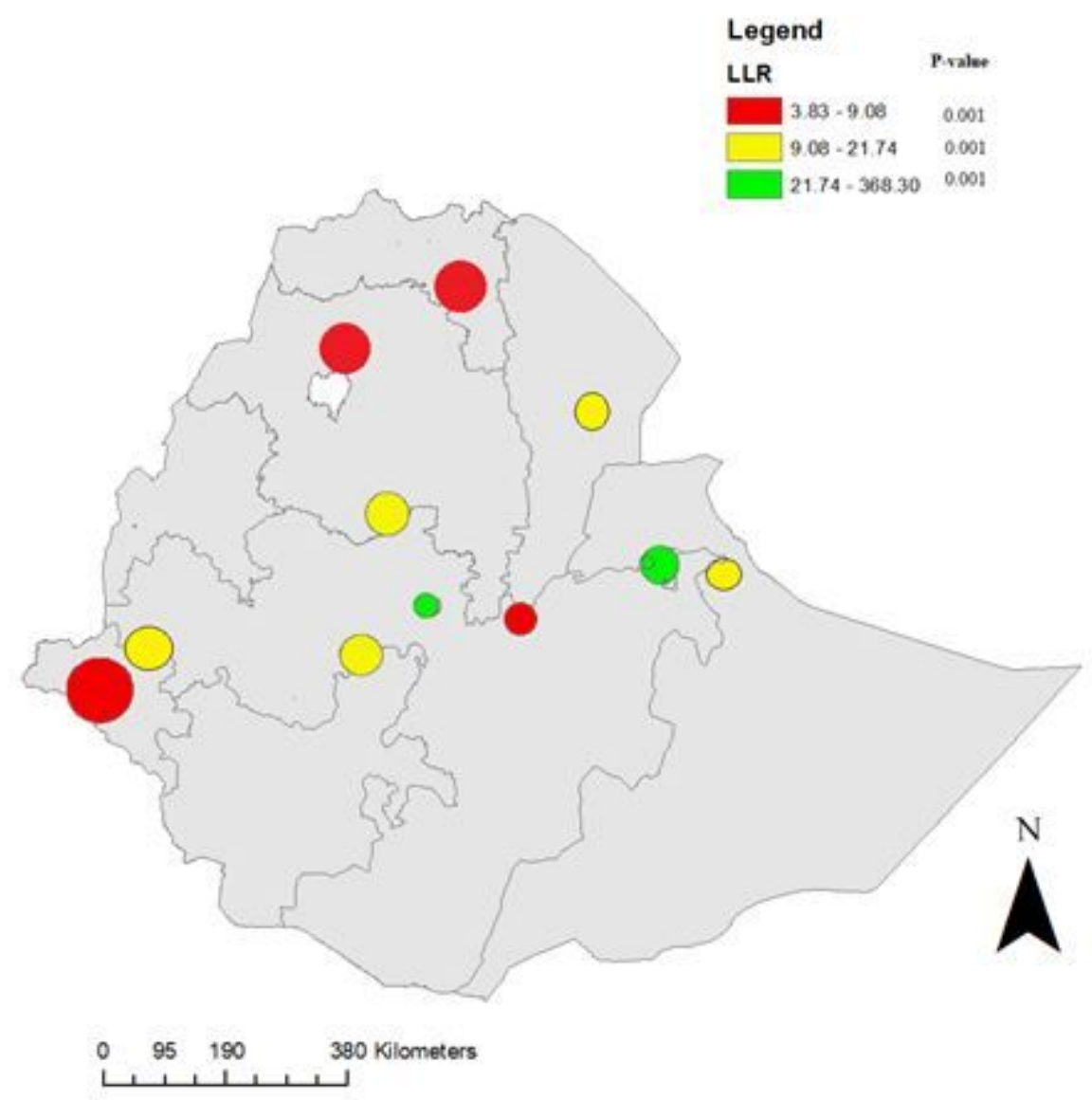

Figure 4

Spatial scan statistics of skilled birth attendant across the regions of Ethiopia in EDHS 2011 


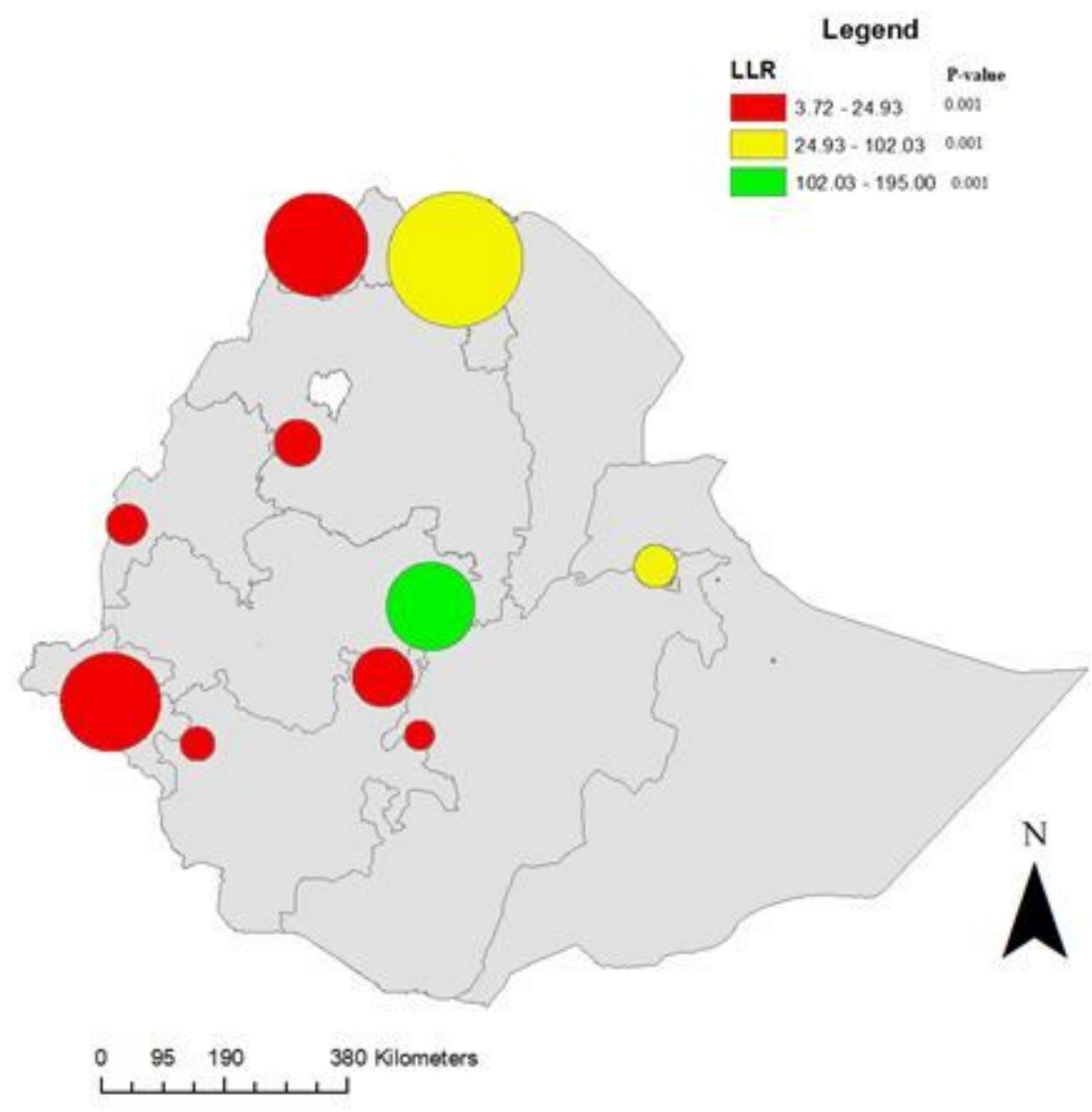

Figure 5

Spatial scan statistics of skilled birth attendant across the regions of Ethiopia, in EDHS 2016 